\title{
Acute and Chronic Toxicity of Prothioconazole and its Metabolite Prothioconazole-Desthio To Daphnia Magna
}

\author{
An Xuehua \\ Zhejiang Academy of Agricultural Sciences \\ Liu Xinju \\ Zhejiang Academy of Agricultural Sciences \\ Jiang Jinhua \\ Zhejiang Academy of Agricultural Sciences \\ Wang Feidi \\ Zhejiang Academy of Agricultural Sciences \\ Lv Lu \\ Zhejiang Academy of Agricultural Sciences \\ Li Gang \\ Zhejiang Academy of Agricultural Sciences \\ Wu Shenggan \\ Zhejiang Academy of Agricultural Sciences \\ Zhao Xueping ( $\square$ anxh@zaas.ac.cn ) \\ Zhejiang Academy of Agricultural Sciences
}

Research Article

Keywords: Prothioconazole, prothioconazole-desthio, Daphnia magna, acute toxicity, chronic toxicity

Posted Date: July 24th, 2021

DOI: https://doi.org/10.21203/rs.3.rs-692338/v1

License: @) (1) This work is licensed under a Creative Commons Attribution 4.0 International License. Read Full License 


\begin{abstract}
Prothioconazole (PTC) is a broad-spectrum triazole fungicide. Current research has mainly focused on its efficacy and residues, with few studies on its toxicological effects. This study assessed the effects of PTC, and its metabolite prothioconazole-desthio (PTCd), on the inhibition of activity, growth, and reproduction of Daphnia magna using acute and chronic toxicity tests. Additionally, the dose-response relationship was established to determine sensitive biological indicators. The acute toxicity test shows that the $48 \mathrm{~h} \mathrm{EC} \mathrm{E}_{50}$ of PTC and PTCd to D. magna were 2.82 and $5.19 \mathrm{mg} / \mathrm{L}$, respectively. The chronic toxicity of PTC and PTCd to D. magna were 0.00860 and $0.132 \mathrm{mg} / \mathrm{L}$, respectively, with the parent compound being 15.3 times more toxic than its metabolite. The acute to chronic toxicity ratio (ACR) was calculated using chronic toxicity data, with ACR values of 227 and 27.5 for PTC and PTCd, respectively. These results indicate that both PTC and PTCd affect the growth and reproduction of $D$. magna, and the toxicity of the parent compound is greater than that of its metabolite. In conclusion, the metabolites of this pesticide have sufficient toxicity to harm $D$. magna at relevant environmental concentrations, and their environmental risk should not be neglected.
\end{abstract}

\title{
1. Introduction
}

Pesticides, and other aquatic ecosystem pollutants, widely exist in water, causing serious environmental problems. Pesticides in the aquatic environment can directly harm Daphnia, fish, algae, and other aquatic organisms, invariably affecting human health through consumption of the polluted water or via the aquatic food chain. Therefore, it is necessary to evaluate the effects of pesticides on aquatic organisms.

Daphnia magna is a representative aquatic zooplankton and an important intermediate connecting the aquatic biological chain. It has a critical role in purifying water, and its primary production directly affects the structure and function of aquatic ecosystems. Growth and activity inhibitions are the initial responses of $D$. magna to environmental perturbations and can be used as a sensitive toxicity indicator. Hence, D. magna has gained global attention due to its significant role in aquatic ecosystems and is an important research subject, particularly in aquatic toxicology (Hu et al. 2018; Liu et al. 2018).

Prothioconazole (PTC), a triazole fungicide that inhibits demethylation of sterol precursors 14-lanosterol or 24-methylene, is an effective agent in controling various plant diseases. Launched in 2004, PTC is currently registered and sold in over 60 countries (Sjerps et al. 2019). It has become one of the world's bestselling fungicides (Zhang et al. 2018), with global sales exceeding US\$800 million in 2014 (Zhang et al. 2020). PTC usually transforms gradually into prothioconazole-desthio (PTCd) (Xie et al. 2019; Haas and Justus 2004; Hellpointner and Borchers 2004), which is a major metabolite in photolysis and plant metabolism and has certain teratogenicity (Hoaip et al. 2011; Hasan et al. 2019). Therefore, it is critical to evaluate the effects of both PTC and PTCd. Most existing studies on PTC are related to PTC residues in soil, fruits, vegetables, wheat, and animal products (Deb et al. 2010; Paul et al. 2019), with few studies reporting PTC toxicity on aquatic organisms. In this study, acute and chronic toxicity tests of PTC and PTCd on D. magna were conducted to provide a theoretical basis for the evaluation of their effects. The results can also provide fundamental data for the assessment of the aquatic environmental risk of PTC and offer a scientific basis for the protection of aquatic ecosystems.

\section{Materials And Methods}

\subsection{Reagents and instruments}

D. magna was fed Pseudokirchneriella subcapitata and was cultured and propagated in Elendt M4 base in the laboratory (Zhejiang Academy of Agricultural Sciences). Healthy, non-first-born Daphnia with parthenogenetic reproduction of more than three generations, and individuals aged $<24 \mathrm{~h}$ were selected for the toxicity tests.

PTC (98.0\%, CAS 178928-70-6) and PTCd (98.0\%, CAS 120983-64-4) were provided by Dr. Ehrenstorfer GmbH and Sigma-Aldrich, respectively. The following reagents were used: Acetonitrile (Merck \& Co.), formic acid (Anaqua ${ }^{\text {TM }}$ Chemicals Supply), and acetone (Yonghua Chemical Technology [Jiangsu] Co. Ltd.). The following instruments were used for the analysis: Exion LCAD-Triple Quad ${ }^{\mathrm{Tm}} 5500$ (ABsciex Co. U.S.), an ACQUITY UPLCTM BEH C 18 column (2.1 mm $\times 100$ $\mathrm{mm} \times 1.7 \mu \mathrm{m})\left(\right.$ Waters $^{\mathrm{TM}}$ Corporation, U.S.), and a light incubator (Sanyo MLR-350HT, SANYO Electric CO. Japan).

\subsection{Test method}

\subsubsection{Acute toxicity test}

The acute toxicity test was conducted according to the updated OECD guideline 202 for Daphnia sp. Acute Immobilization Test (OECD 2006). Test solutions were prepared with Elendt M4 base based on the pre-test. In this study, PTC test concentrations were 2.21, 2.65, 3.1, 3.82, 4.58, and 5.50 mg/L, and those of PTCd were $3.23,3.88,4.64,5.56,6.67$, and $8.00 \mathrm{mg} / \mathrm{L}$. In addition, the blank and solvent control groups were set.

The "semi-static method" was employed for the PTC test, and the test solution was changed $24 \mathrm{~h}$ after the test. The "static method" was employed for the PTCd test, and the test solution remained the same throughout the test period. The test solution was first filtered using $0.45 \mu \mathrm{m}$ membrane filters, and a $50 \mathrm{~mL}$ solution was added to the crystallizing dish ( $60 \mathrm{~mm}$ diameter). Five test Daphnia species were added to each dish and then placed into the light incubator. Each treatment group and the control group had four replicates, with one dish for each replicate. The experimental period was $48 \mathrm{~h}$, and no bait was added during this period. The condition for PTC was darkness throughout, and $16 \mathrm{~h}$ light and $8 \mathrm{~h}$ darkness for PTCd.

During the acute toxicity test, PTC samples were subjected to concentration analysis at the beginning of the test $(0 \mathrm{~h})$ and $24 \mathrm{~h}$ before the test solution was changed. PTCd was sampled at the beginning and end of the experiment for concentration analysis.

\subsubsection{Chronic toxicity test}

Page $2 / 9$ 
The 21-day chronic toxicity test was conducted based on the updated OECD guideline 211 for Daphnia sp. (OECD 1998). According to the acute toxicity test results of PTC and PTCd to D. magna, PTC test concentrations were $0.0125,0.0250,0.0500,0.100,0.200$, and $0.400 \mathrm{mg} / \mathrm{L}$, and those of PTCd were 0.0315 , $0.0630,0.126,0.250,0.500,0.500$, and $1.00 \mathrm{mg} / \mathrm{L}$. The blank and solvent control groups were set. Thirteen replicates (crystallizing dishes) were set in each test group, each containing $50 \mathrm{~mL}$ test solution and one parent Daphnia. The light condition was $16 \mathrm{~h}$ light and $8 \mathrm{~h}$ darkness, and the test period was $21 \mathrm{days}$. The PTC test solution was changed every $24 \mathrm{~h}$, whereas that of PTCd was changed every three days. Samples were taken irregularly throughout the experiment (see Table 4 for sampling times) to estimate the actual concentrations of PTC and PTCd in the test solution.

During the experiment, the appearance and survival of the parent Daphnia were observed daily, newborn Daphnia species were removed on time, and the number of living offspring was calculated. Furthermore, the mortality of parent Daphnia and the number of broods per parent Daphnia were recorded. At the end of the experiment, the body length of all surviving parent Daphnia was also measured.

\subsection{Concentration analysis}

\subsubsection{Sample pretreatment}

Approximately $5 \mathrm{~mL}$ of the test solution sample was obtained and diluted to $10 \mathrm{~mL}$ with acetonitrile (constant volume) and vortexed for $30 \mathrm{~s}$. Then, it was filtered with a $0.22 \mu \mathrm{m}$ membrane filter or diluted with acetonitrile:water (1:1, v/v) and filtered with a $0.22 \mu \mathrm{m}$ membrane filter for analysis.

\subsubsection{Test conditions}

The Exion LCAD-Triple Quad ${ }^{\text {TM }} 5500$ was used for high-performance liquid chromatography (HPLC), with the following conditions: ACQUITY UPLCTM BEH $\mathrm{C}_{18}$ column $(2.1 \mathrm{~mm} \times 100 \mathrm{~mm} \times 1.7 \mu \mathrm{m})$, gradient elution with $0.2 \%$ acetic acid $+5 \mathrm{mmol} / \mathrm{L}$ ammonium acetate solution and acetonitrile, and flow velocity: 30 $\mathrm{mL} / \mathrm{min}$. The retention times of PTC and PTCd were approximately 3.2 and $2.8 \mathrm{~min}$, respectively.

The mass spectrum conditions were as follows: capillary voltage, $5.5 \mathrm{kV}$; air curtain gas, 35 psi; collision gas, 7 psi; spray gas, 50 psi; auxiliary heating gas, 50 psi; ion source temperature, $550^{\circ} \mathrm{C}$; collision cell entrance voltage, $10 \mathrm{~V}$; and collision cell outlet voltage, $16 \mathrm{~V}$. The qualitative and quantitative modes involved multiple reaction monitoring, and an electrospray ionization source operated in the positive mode. The other mass spectrometric analysis parameters are shown in Table 1.

Table 1 Mass spectrometric analysis parameters for prothioconazole (PTC) and prothioconazole-desthio (PTCd).

\begin{tabular}{|llllll|}
\hline Replicate & Parent ion & Daughter ion & $\begin{array}{l}\text { Dwell time } \\
(\mathbf{m s})\end{array}$ & Declustering potential $(\mathrm{V})$ & Collision energy $(\mathrm{V})$ \\
\hline PTC & $343.7(343.7)$ & $326.0(154.2)$ & $100(100)$ & $100(100)$ & $12(30)$ \\
\hline PTCd & $312.2(312.2)$ & $70.0(125.2)$ & $100(100)$ & $140(140)$ & $38(47)$ \\
\hline \multicolumn{4}{l}{ Note: The numbers in () are qualitative ions. }
\end{tabular}

\subsection{Statistical analysis}

\subsubsection{Acute toxicity test}

SPSS 16.0 (IBM, USA) was used for regression analysis to establish a "dose-response" linear relationship and calculate $\mathrm{EC}_{50}$ (concentration for $50 \%$ of maximal effect) and $95 \%$ confidence intervals $(\mathrm{Cl})$, based on the measured concentration of the test solution and inhibition rate of $D$. magna activity for each treatment group.

\subsubsection{Chronic toxicity test}

SPSS was used to perform one way ANOVA and Williams tests, based on the measured concentration of test solution and various indicators (toxicity data of the time of the first presenting offspring, number of broods per parent Daphnia, total number of living offspring produced by each parent, and body length of each surviving Daphnia). $P<0.05$ indicated a significant difference.

\section{Results And Discussion}

\subsection{Pesticide stability and method accuracy}

The stability of PTC and PTCd in the Elendt M4 medium is shown in Table 2. The results show that within a certain concentration range (0.0005-100 mg/L), the quantitative ion peak area of PTC and PTCd in the blank medium (Elendt M4) had a good linear relationship with the injection volume and concentration, and the correlation coefficients were $>0.9990$.

The accuracy of the method was evaluated by adding PTC and PTCd in the blank medium (Elendt M4). Consequently, the average recoveries of PTC and PTCd were $93.8-97.8 \%$ and $97.8-102 \%$, respectively. Hence, this test met the average recovery requirement of $70-120 \%$ (OECD 2006). 
Table 2

Regression equation limits of quantity and average recovery of prothioconazole (PTC) and prothioconazole-desthio (PTCd) in the Elendt M4 medium.

\begin{tabular}{|llllll|}
\hline Replicate & Regression equation & Correlation coefficient & $\begin{array}{l}\text { Quantity limit } \\
(\mathrm{mg} / \mathrm{L})\end{array}$ & $\begin{array}{l}\text { Added concentration } \\
(\mathrm{mg} / \mathrm{L})\end{array}$ & $\begin{array}{l}\text { Average recovery } \\
(\%)\end{array}$ \\
\hline PTC & $y=29113876 x-11345$ & 0.9999 & 0.00200 & $0.00200,20.0$ & $93.8-97.8$ \\
\hline PTCd & $y=9004111 x-450$ & 0.9999 & 0.00200 & $0.00200,20.0$ & $97.8-102$ \\
\hline
\end{tabular}

\subsection{Concentration analysis of test solution}

During the acute toxicity test of PTC and PTCd, water samples were collected at the beginning of the test $(0 \mathrm{~h})$ and $24 \mathrm{~h}$ before the test solution was changed at the end of the test $(48 \mathrm{~h}$ ) for concentration analysis. The corresponding results are presented in Table 3 . The measured concentration of PTC at $24 \mathrm{~h}$ before the test solution replacement was $53.3-72.4 \%$ of the measured concentration at $0 \mathrm{~h}$, indicating that degradation occurred in this study environment (Xie et al. 2019). However, the measured concentration of PTCd at $48 \mathrm{~h}$ was $95.9-102 \%$ of the measured concentration at $0 \mathrm{~h}$, and the concentration variation was < $20 \%$, indicating a relatively stable test period. The geometric mean values of the measured concentration of PTC at $0 \mathrm{~h}$ and $24 \mathrm{~h}$ (before test solution replacement) were calculated based on the test guidelines of environmental safety assessment for chemical pesticides (OECD 2006). In addition, the geometric mean values of the measured concentrations of PTCd at $0 \mathrm{~h}$ and $48 \mathrm{~h}$ were also calculated. These mean values were used to measure the acute toxicity of PTC and PTCd to D. magna.

Table 3

Analysis of prothioconazole (PTC) and prothioconazole-desthio (PTCd) concentrations in the acute toxicity test.

\begin{tabular}{|c|c|c|c|c|c|}
\hline Replicate & $\begin{array}{l}\text { Theoretical } \\
\text { concentration } \\
(\mathrm{mg} / \mathrm{L})\end{array}$ & $\begin{array}{l}\text { Measured concentration } \\
\text { at } \mathrm{O} \mathrm{h} \\
(\mathrm{mg} / \mathrm{L})\end{array}$ & $\begin{array}{l}\text { Measured concentration } \\
\text { at } 24 \mathrm{~h} \\
(\mathrm{mg} / \mathrm{L})\end{array}$ & $\begin{array}{l}\text { Measured } \\
\text { concentration } \\
(\mathrm{mg} / \mathrm{L})\end{array}$ & $\begin{array}{l}\text { Ratio of } 24 \mathrm{~h} \text { concentration by } 0 \mathrm{~h} \\
\text { concentration } \\
\text { (\%) }\end{array}$ \\
\hline \multirow[t]{6}{*}{ PTC } & 5.50 & 4.89 & 3.22 & 3.97 & 65.8 \\
\hline & 4.58 & 3.52 & 2.21 & 2.79 & 62.8 \\
\hline & 3.82 & 3.60 & 1.92 & 2.63 & 53.3 \\
\hline & 3.18 & 2.88 & 1.58 & 2.13 & 54.9 \\
\hline & 2.65 & 2.21 & 1.60 & 1.88 & 72.4 \\
\hline & 2.21 & 2.05 & 1.23 & 1.59 & 60.0 \\
\hline \multirow[t]{2}{*}{ Replicate } & $\begin{array}{l}\text { Theoretical } \\
\text { concentration }\end{array}$ & $\begin{array}{l}\text { Measured concentration } \\
\text { at } 0 \mathrm{~h}\end{array}$ & $\begin{array}{l}\text { Measured concentration } \\
\text { at } 48 \mathrm{~h}\end{array}$ & $\begin{array}{l}\text { Measured } \\
\text { concentration }\end{array}$ & $\begin{array}{l}\text { Ratio of } 48 \mathrm{~h} \text { concentration by } 0 \mathrm{~h} \\
\text { concentration }\end{array}$ \\
\hline & (mg/L) & (mg/L) & (mg/L) & $(\mathrm{mg} / \mathrm{L})$ & (\%) \\
\hline \multirow[t]{6}{*}{ PTCd } & 8.00 & 7.00 & 7.10 & 7.05 & 101 \\
\hline & 6.67 & 6.23 & 6.33 & 6.28 & 102 \\
\hline & 5.56 & 5.44 & 5.34 & 5.39 & 98.2 \\
\hline & 4.64 & 4.31 & 4.21 & 4.26 & 97.7 \\
\hline & 3.88 & 3.66 & 3.54 & 3.60 & 96.7 \\
\hline & 3.23 & 3.18 & 3.05 & 3.11 & 95.9 \\
\hline
\end{tabular}

The PTC and PTCd concentrations during the chronic toxicity test were analyzed, and the results are presented in Table 4 . Table 4 shows that the variation between the PTC concentration in the test solution and the initial determined concentration is $> \pm 20 \%$ throughout the test period. According to OECD 211 (OECD 1998), considering the long-term effect of PTC on D. magna, the reproductive toxicity test concentration of PTC can be represented as the timeweighted arithmetic mean value of measured concentration during the test. Table 4 indicates that the PTCd concentration in the test solution remained at $> \pm$ $20 \%$ of the initial determined concentration throughout the test period. Therefore, the reproductive toxicity test concentration of PTCd can be represented as the geometric mean value of the measured concentration (OECD 1998). 
Table 4

Chronic toxicity test results of prothioconazole (PTC) and prothioconazole-desthio (PTCd).

\begin{tabular}{|c|c|c|c|c|c|c|c|c|c|c|c|c|c|}
\hline \multirow{2}{*}{$\begin{array}{l}\text { Theoretical } \\
\text { concentration } \\
\text { (mg/L) }\end{array}$} & \multicolumn{13}{|c|}{ PTC measured concentration (mg/L) } \\
\hline & $0 \mathrm{~d}$ & $1 \mathrm{~d}$ old & $1 \mathrm{~d}$ new & $2 \mathrm{~d}$ old & $\begin{array}{l}2 \mathrm{~d} \\
\text { new }\end{array}$ & $3 \mathrm{~d}$ old & $\begin{array}{l}3 \mathrm{~d} \\
\text { new }\end{array}$ & $4 \mathrm{~d}$ old & $9 \mathrm{~d}$ new & $10 \mathrm{~d}$ old & $\begin{array}{l}15 d \\
\text { new }\end{array}$ & $16 \mathrm{~d}$ old & $\begin{array}{l}20 \mathrm{~d} \\
\text { new }\end{array}$ \\
\hline 0.400 & 0.462 & 0.352 & 0.348 & 0.331 & 0.383 & 0.266 & 0.414 & 0.273 & 0.337 & 0.288 & 0.400 & 0.273 & 0.37 \\
\hline 0.200 & 0.220 & 0.147 & 0.163 & 0.125 & 0.179 & 0.1019 & 0.206 & 0.125 & 0.160 & 0.107 & 0.171 & 0.113 & 0.16 \\
\hline 0.100 & 0.111 & 0.0747 & 0.0845 & 0.0503 & 0.1065 & 0.0568 & 0.103 & 0.0626 & 0.0894 & 0.0626 & 0.099 & 0.0546 & 0.09 \\
\hline 0.0500 & 0.0576 & 0.0353 & 0.0470 & 0.0279 & 0.0628 & 0.0295 & 0.0558 & 0.0305 & 0.0457 & 0.0277 & 0.0514 & 0.0279 & 0.05 \\
\hline 0.0250 & 0.0267 & 0.0161 & 0.0211 & 0.0116 & 0.0264 & 0.0113 & 0.0250 & 0.0154 & 0.0215 & 0.0123 & 0.0221 & 0.0117 & 0.02 \\
\hline 0.0125 & 0.0127 & 0.00591 & 0.00970 & 0.00470 & 0.0133 & 0.00559 & 0.0120 & 0.00677 & 0.00981 & 0.00592 & 0.0101 & 0.00609 & 0.01 \\
\hline $\begin{array}{l}\text { Theoretical } \\
\text { concentration }\end{array}$ & \multicolumn{13}{|c|}{ PTCd measured concentration (mg/L) } \\
\hline (mg/L) & \multicolumn{2}{|l|}{$0 \mathrm{~d}$} & \multicolumn{2}{|c|}{$3 \mathrm{~d}$ old } & \multicolumn{2}{|c|}{$9 \mathrm{~d}$ new } & \multicolumn{2}{|c|}{$12 \mathrm{~d}$ old } & & \multicolumn{2}{|c|}{$18 \mathrm{~d}$ new } & \multicolumn{2}{|c|}{$21 \mathrm{~d}$} \\
\hline 1.00 & \multicolumn{2}{|l|}{0.923} & \multicolumn{2}{|c|}{0.916} & \multicolumn{2}{|c|}{0.951} & \multicolumn{2}{|c|}{1.020} & & \multicolumn{2}{|c|}{1.150} & \multicolumn{2}{|c|}{0.951} \\
\hline 0.500 & \multicolumn{2}{|l|}{0.486} & \multicolumn{2}{|c|}{0.492} & \multicolumn{2}{|c|}{0.502} & \multicolumn{2}{|c|}{0.512} & & \multicolumn{2}{|c|}{0.513} & \multicolumn{2}{|c|}{0.492} \\
\hline 0.250 & \multicolumn{2}{|l|}{0.266} & \multicolumn{2}{|c|}{0.356} & \multicolumn{2}{|c|}{0.256} & \multicolumn{2}{|c|}{0.230} & & \multicolumn{2}{|c|}{0.263} & \multicolumn{2}{|c|}{0.256} \\
\hline 0.126 & \multicolumn{2}{|l|}{0.129} & \multicolumn{2}{|c|}{0.123} & \multicolumn{2}{|c|}{0.130} & \multicolumn{2}{|c|}{0.155} & & \multicolumn{2}{|c|}{0.130} & \multicolumn{2}{|c|}{0.125} \\
\hline 0.0630 & \multicolumn{2}{|l|}{0.0629} & 0.0 & & 0.0 & 31 & 0.0 & 82 & & 0.0 & & 0.0 & \\
\hline 0.0315 & 0.0320 & & 0.0 & & 0.0 & 15 & 0.0 & 96 & & 0.03 & & 0.0 & \\
\hline
\end{tabular}

Note: ${ }^{\text {a }}$ The measured concentration is the time-weighted average concentration of PTC/PTCd in the test solution.

\subsection{Toxicity to D. magna}

\subsubsection{Acute toxicity}

Pesticide metabolites are critical in evaluating the ecological risk of pesticides (Wang et al. 2016). D. magna activity inhibition test can indicate the degree of triazole fungicide pollution in the aquatic ecosystem (Cassani et al. 2013).

In the acute toxicity activity inhibition test, $D$. magna in the blank and solvent control groups grew normally without any mortality. At $48 \mathrm{~h}$ exposure to PTC concentrations of $1.59,1.88,2.13,2.63,2.79$, and $3.97 \mathrm{mg} / \mathrm{L}, \mathrm{D}$. magna activity was inhibited by $10,20,30,40,55$, and $75 \%$, respectively. At PTCd concentrations of $3.11,3.60,4.26,5.39,6.28$, and $7.05 \mathrm{mg} / \mathrm{L}, \mathrm{D}$. magna activity was inhibited by $15,25,30,50,60$, and $80 \%$, respectively. Therefore, there was a dose-response relationship, with increasing exposure concentrations causing increased inhibition of $D$. magna activity. Table 5 shows that the $24 \mathrm{~h}$ and $48 \mathrm{~h}$ $\mathrm{EC}_{50}$ of PTC to $D$. magna were $3.11 \mathrm{mg} / \mathrm{L}(95 \% \mathrm{Cl} 2.91-3.32 \mathrm{mg} / \mathrm{L})$ and $2.82 \mathrm{mg} / \mathrm{L}(95 \% \mathrm{Cl} 2.69-2.95 \mathrm{mg} / \mathrm{L})$, respectively, while those of PTCd to $D$. magna were $5.93 \mathrm{mg} / \mathrm{L}(95 \% \mathrm{Cl} 5.47-6.44 \mathrm{mg} / \mathrm{L})$ and $5.19 \mathrm{mg} / \mathrm{L}(95 \% \mathrm{Cl} 4.89-5.51 \mathrm{mg} / \mathrm{L})$, respectively. Zhai et al. (2019) revealed that the $48 \mathrm{~h} \mathrm{EC}_{50}$ of PTC to $D$. magna was $2.68 \mathrm{mg} / \mathrm{L}$, which is consistent with the results of the present study. Sinclair and Boxall (2003) observed that the toxicity of $70 \%$ of degradation products was almost equal to, or less than, that of the parent compound. In this study, PTC, and its metabolite PTCd, were found to have similar toxicities. Although triazole fungicides have similar structures, they have significantly different acute inhibition of $D$. magna activity (Guo et al. 2009). Additionally, their residues in the environment may have harmful effects on humans (Trösken et al. 2006; Trösken et al. 2004); therefore, it is necessary to assess the chronic toxicity of triazole fungicides to $D$. magna. 
Table 5

The $24 \mathrm{~h}$ and $48 \mathrm{~h}$ EC50 values of prothioconazole (PTC) and its metabolite prothioconazole-desthio (PTCd) to Daphnia magna.

\begin{tabular}{|c|c|c|c|c|c|}
\hline Replicate & $\begin{array}{l}\text { Exposure } \\
\text { (h) }\end{array}$ & Toxicity regression equations & Correlation coefficient & $\begin{array}{l}48 \mathrm{~h}-\mathrm{EC}_{50} \\
(\mathrm{mg} / \mathrm{L})\end{array}$ & $\begin{array}{l}95 \% \text { confidence intervals } \\
(\mathrm{mg} / \mathrm{L})\end{array}$ \\
\hline \multirow[t]{2}{*}{ PTC } & 24 & $y=3.0717+4.0225 x$ & 0.9859 & 3.11 & $2.91-3.32$ \\
\hline & 48 & $y=2.8012+4.8901 x$ & 0.9906 & 2.82 & $2.69-2.95$ \\
\hline \multirow[t]{2}{*}{ PTCd } & 24 & $y=1.4294+4.6176 x$ & 0.9755 & 5.93 & $5.47-6.44$ \\
\hline & 48 & $y=1.5509+4.8208 x$ & 0.9808 & 5.19 & $4.89-5.51$ \\
\hline
\end{tabular}

\subsubsection{Chronic toxicity}

Growth and development status, as well as reproductive capacity, are sensitive indicators to evaluate the chronic toxicity of pesticides to $D$. magna. Furthermore, these indicators are key parameters to evaluate the population's growth capacity (Kim et al. 2012). The chronic toxicity test showed that the mortality of Daphnia in the blank and solvent control groups was 0 . Moreover, no significant differences were observed in the toxicity data of the time of the first presenting offspring, the number of broods per parent Daphnia, the total number of living offspring produced by each parent, or the body length of each surviving Daphnia $(P>0.05)$. Therefore, the blank and solvent control groups were combined (combination control) and used to analyze the difference between each treatment group. The results are presented in Table 6.

There was no significant difference between the $0.00860 \mathrm{mg} / \mathrm{L} \mathrm{PTC}$ treatment and the combination control groups (Table 6). However, with increasing PTC concentrations, the total number of juveniles produced by each surviving parent Daphnia decreased significantly. Moreover, the number of broods per parent Daphnia, and the body length of each surviving parent were inhibited to varying degrees. Particularly, in the maximum concentration group ( $0.341 \mathrm{mg} / \mathrm{L})$, the time of the first presenting offspring was significantly inhibited. Additionally, the number of broods per parent Daphnia, total number of living offspring produced by each surviving parent, and body length of each surviving parent were significantly reduced, and the reproductive capacity was seriously inhibited. Using the body length of each surviving parent as the toxicity index, the no observed effect concentration (NOEC) of PTC to D. magna at 21 days was 0.00860 $\mathrm{mg} / \mathrm{L}$, and the lowest observed effect concentration (LOEC) was $0.0180 \mathrm{mg} / \mathrm{L}$.

Table 6 shows that there was no significant difference between PTCd treatments at concentrations of $0.0317-0.132 \mathrm{mg} / \mathrm{L}$ and the combination control group. However, at a PTCd concentration of $0.982 \mathrm{mg} / \mathrm{L}$, a significant difference was observed in the time of the first presenting offspring $(P<0.05)$. The number of broods per parent Daphnia and the body length of each surviving parent were significantly inhibited when the concentration was $0.499-0.982 \mathrm{mg} / \mathrm{L}(P<0.05)$. Moreover, when the concentration was $0.269-0.982 \mathrm{mg} / \mathrm{L}$, the total number of living offspring produced by each surviving Daphnia was significantly reduced $(P<0.05)$. Using the total number of living offspring produced by each surviving Daphnia as the toxicity index, the NOEC of PTC to $D$. magna at 21 days was $0.132 \mathrm{mg} / \mathrm{L}$, and the LOEC was $0.269 \mathrm{mg} / \mathrm{L}$.

There was a 15.3-fold difference between the NOEC of PTC and PTCd at 21 days in D. magna, and the parent compound was more toxic than its metabolites. Therefore, the long-term chronic threat of PTC to aquatic organisms should not be ignored. Furthermore, Cassani et al. (2013) proposed that triadimenol could lead to a higher abnormality rate in the $D$. magna offspring, resulting in a decreased and rare population of $D$. magna. Therefore, the environmental risks caused by widely used triazole fungicides should be assessed.

\subsection{Acute-chronic toxicity ratio}

Chronic toxicity tests require a long time period, complex test conditions, and significant manpower and material resources. Hence, fixed factor methods have been developed to evaluate the chronic effects of harmful substances in the environment, such as the acute-chronic toxicity ratio (ACR). According to previous studies (Rodriguez et al. 2006; Yuan 2012), the ACR can predict the safety concentration when chronic toxicity data regarding environmental risk assessments are lacking. Table 7 presents the NOEC and LOEC of PTC and PTCd to D. magna based on four biological indexes, including the time of the first presenting offspring, number of broods per parent Daphnia, total number of living offspring, and body length of the living parent. The application factors (AFs) and ACR of PTC and PTCd to D. magna were determined in combination with the acute and chronic toxicity test results. In Table 7, $\mathrm{AF}=\mathrm{ChV} / 48 \mathrm{~h} \mathrm{EC} \mathrm{F}_{5}$, where $\mathrm{ChV}$ represents the chronic value, which is the geometric mean of NOEC and LOEC. ACR 1 was calculated by $48 \mathrm{~h} \mathrm{EC}{ }_{50} / \mathrm{ChV}_{\text {. }} \mathrm{Meanwhile}_{\mathrm{ACR}}\left(\mathrm{ACR}_{2}=48 \mathrm{~h} \mathrm{EC} \mathrm{C}_{50} / 48\right.$ $\mathrm{h} \mathrm{EC} \mathrm{C}_{10}$ ), calculated using acute toxicity $\mathrm{EC}_{10}$, was compared with $\mathrm{ACR}_{1}$. The AFs of PTC and PTCd were 0.00441 and 0.0363 , respectively, which had one order of magnitude difference. Kuhn et al. (1989) measured the NOEC and $24 \mathrm{~h} \mathrm{EC} \mathrm{E}_{50}$ of 73 environmental pollutants to $D$. magna and compared their $\mathrm{AF}$ values. Some AF values varied by three orders of magnitude, whereas some values varied by $5-9$ fold.

Rodriguez et al. (2006) calculated the ACR by dividing the acute toxicity $48 \mathrm{~h} \mathrm{EC} \mathrm{E}_{50}$ by chronic toxicity data. Yuan (2012) calculated the ACR by replacing chronic toxicity data with acute toxicity $\mathrm{EC}_{10}$. The $\mathrm{ACR}_{1}$ values obtained from chronic toxicity data for PTC and PTCd in this study were 227 and 27.5 , respectively. The $A C R_{2}$ values calculated from the acute toxicity data $\mathrm{EC}_{10}$ for $\mathrm{PTC}$ and $\mathrm{PTCd}$ were 1.83 and 1.84 , respectively. Thus, $A C R_{1}$ is closer to the recommended value of 100 (Ahlers et al. 2006), thereby indicating that $A C R_{1}$ is a more suitable ACR. In this study, the ACR 1 of PTC was 124 times higher than $\mathrm{ACR}_{2}$, and $\mathrm{ACR}_{1}$ of PTCd was 15 times higher than $\mathrm{ACR}_{2}$. This establishes that replacing chronic toxicity data NOEC with acute toxicity data EC 10 might have 
a significant impact on ACR in environmental risk assessment. Therefore, when chronic toxicity data are lacking, ACR should be cautiously used to predict the safe concentration.

Table 6

Summary of all endpoints observed in the chronic test of prothioconazole (PTC) and prothioconazole-desthio (PTCd) to Daphnia magna.

\begin{tabular}{|c|c|c|c|c|c|c|c|}
\hline Replicate & $\begin{array}{l}\text { Measured } \\
\text { concentration } \\
\text { (mg/L) }\end{array}$ & $\begin{array}{l}\text { Number of } \\
\text { parent } \\
\text { Daphnia }\end{array}$ & $\begin{array}{l}\text { Mortality of } \\
\text { parent } \\
\text { Daphnia }\end{array}$ & $\begin{array}{l}\text { Time of the first } \\
\text { presenting offspring } \\
\text { (d) }\end{array}$ & $\begin{array}{l}\text { Number of brood } \\
\text { per parent } \\
\text { Daphnia }\end{array}$ & $\begin{array}{l}\text { Total number of } \\
\text { living offspring }\end{array}$ & $\begin{array}{l}\text { Body length of living } \\
\text { parent Daphnia (mm) }\end{array}$ \\
\hline \multirow[t]{9}{*}{ PTC } & 0.341 & 13 & 0 & $9.8 \pm 1.8^{*}$ & $6.08 \pm 1.04^{*}$ & $127 \pm 23.5^{*}$ & $3.034 \pm 0.091^{*}$ \\
\hline & 0.155 & 13 & 1 & $6.5 \pm 0.5$ & $7.15 \pm 1.41^{*}$ & $172 \pm 26.2^{*}$ & $3.165 \pm 0.129^{*}$ \\
\hline & 0.0807 & 13 & 1 & $6.5 \pm 0.9$ & $6.85 \pm 2.15^{*}$ & $212 \pm 43.4^{*}$ & $3.306 \pm 0.132^{*}$ \\
\hline & 0.0405 & 13 & 0 & $6.0 \pm 0$ & $8.00 \pm 0.58^{*}$ & $355 \pm 29.4^{*}$ & $3.351 \pm 0.104^{*}$ \\
\hline & 0.0180 & 13 & 1 & $6.0 \pm 0$ & $8.31 \pm 2.53$ & $337 \pm 38.9$ & $3.393 \pm 0.100^{*}$ \\
\hline & 0.00860 & 13 & 0 & $6.1 \pm 0.1$ & $8.85 \pm 0.55$ & $382 \pm 31.3$ & $3.477 \pm 0.186$ \\
\hline & $\begin{array}{l}\text { Combination } \\
\text { control }\end{array}$ & 26 & 0 & $6.3 \pm 0.5$ & $9.08 \pm 0.74$ & $374 \pm 23.9$ & $3.505 \pm 0.098$ \\
\hline & 21d-LOEC & - & - & 0.341 & 0.0405 & 0.0405 & 0.0180 \\
\hline & 21d-NOEC & - & - & 0.155 & 0.0180 & 0.0180 & 0.00860 \\
\hline \multirow[t]{9}{*}{ PTCd } & 0.982 & 13 & 0 & $7.1 \pm 1.2^{*}$ & $7.0 \pm 2.1^{*}$ & $250 \pm 30.4^{*}$ & $3.751 \pm 0.131^{*}$ \\
\hline & 0.499 & 13 & 0 & $6.4 \pm 0.3$ & $7.8 \pm 1.8^{\star}$ & $300 \pm 40.9^{*}$ & $3.998 \pm 0.267^{*}$ \\
\hline & 0.269 & 13 & 0 & $6.6 \pm 0.9$ & $8.8 \pm 0.8$ & $339 \pm 61.3^{*}$ & $4.155 \pm 0.114$ \\
\hline & 0.132 & 13 & 0 & $6.1 \pm 0.1$ & $8.2 \pm 1.2$ & $366 \pm 47.6$ & $4.170 \pm 0.112$ \\
\hline & 0.0619 & 13 & 0 & $6.3 \pm 0.5$ & $8.5 \pm 1.0$ & $380 \pm 37.5$ & $4.231 \pm 0.068$ \\
\hline & 0.0317 & 13 & 0 & $6.0 \pm 0$ & $9.1 \pm 1.8$ & $374 \pm 36.8$ & $4.123 \pm 0.212$ \\
\hline & $\begin{array}{l}\text { Combination } \\
\text { control }\end{array}$ & 26 & 0 & $6.1 \pm 0.1$ & $8.7 \pm 0.6$ & $382 \pm 46.2$ & $4.240 \pm 0.110$ \\
\hline & $21 \mathrm{~d}-\mathrm{LOEC}$ & - & - & 0.982 & 0.499 & 0.269 & 0.499 \\
\hline & $21 \mathrm{~d}-\mathrm{NOEC}$ & - & - & 0.499 & 0.269 & 0.132 & 0.269 \\
\hline $\begin{array}{l}\text { Note: The } \\
\text { combinati } \\
\text { Parent Da } \\
\text { concentra }\end{array}$ & $\begin{array}{l}\text { ofured concer } \\
\text { of the blank a } \\
\text { hia that died ac }\end{array}$ & $\begin{array}{l}\text { on is the tim } \\
\text { Ivent contro } \\
\text { itally were }\end{array}$ & $\begin{array}{l}\text { The differenc } \\
\text { ded from the }\end{array}$ & $\begin{array}{l}\text { ncentration of PTC/F } \\
\text { tween the combined } \\
\text { Ilts. LOEC: lowest obs }\end{array}$ & $\begin{array}{l}\text { Cd in the test solut } \\
\text { ntrol group and the } \\
\text { jed effect concentr }\end{array}$ & $\begin{array}{l}\text { Combination con } \\
\text { atment group was } \\
\text { n; NOEC: no obser }\end{array}$ & $\begin{array}{l}\text { ol represents the } \\
\text { significant at } 5 \% \text {. } \\
\text { ed effect }\end{array}$ \\
\hline
\end{tabular}

Table 7

Acute and chronic ratio of prothioconazole (PTC) and prothioconazole-desthio (PTCd) to Daphnia magna.

\begin{tabular}{|c|c|c|c|c|c|c|c|c|}
\hline Replicate & NOEC & LOEC & $48 \mathrm{~h}-\mathrm{EC}_{50}$ & $48 \mathrm{~h}-\mathrm{EC}_{10}$ & ChV & AF & $\mathrm{ACR}_{1}$ & $\mathrm{ACR}_{2}$ \\
\hline PTC & 0.00860 & 0.0180 & 2.82 & 1.54 & 0.0124 & 0.00441 & 227 & 1.83 \\
\hline PTCd & 0.132 & 0.269 & 5.19 & 2.82 & 0.188 & 0.0363 & 27.5 & 1.84 \\
\hline
\end{tabular}

Note: NOEC: no observed effect concentration; LOEC: lowest observed effect concentration; ChV: the geometric mean of NOEC and LOEC; $\mathrm{EC}_{10}$ : concentration for $10 \%$ of maximal effect; $\mathrm{EC}_{50}$ : concentration for $50 \%$ of maximal effect; ACR: acute and chronic ratio.

In conclusion, these results show that PTC, and its metabolite PTCd, have acute and chronic toxicity to $D$. magna. In the natural environment, the exposure of $D$. magna to the concentrations analyzed in this study resulted in a decreasing and rare population of $D$. magna. Therefore, the reproductive and developmental toxicity of PTC to D. magna should be further studied. Moreover, the environmental risk caused by other triazole fungicides should also be assessed.

\section{Declarations}

\section{Ethics approval and consent to participate}

Not applicable 
Consent for publication $囚$ in this section

Not applicable

\section{Availability of data and materials}

Not applicable

\section{Competing interests}

The authors declare that they have no competing interests

\section{Funding}

Funding information is not applicable / No funding was received

\section{Authors' contributions}

All authors contributed to the study conception and design. Material preparation, data collection and analysis were performed by Lui Xinju, Jiang Jinhua, Wang Feidi, Lv Lu, Li Gang, Wu Shenggan, and Zhao Xueping. The first draft of the manuscript was written by An Xuehua and all authors commented on previous versions of the manuscript. All authors read and approved the final manuscript.

\section{References}

1. Ahlers J, Riedhammer C, Vogliano M, Ebert RU, Kühne R (2006) Acute to chronic ratios in aquatic toxicity-Variation across trophic levels and relationship with chemical structure. Environ Toxicol Chem 25:2937-2945

2. Cassani S, Kovarich S, Papa E, Roy PP, Wal VDW, Gramatica P (2013) Daphnia and fish toxicity of (benzo)triazoles: Validated QSAR models, and interspecies quantitative activity-activity modelling. J Hazard Mater 258-259:50-60

3. Deb D, Engel BA, Harbor J, Hahn L, Lim kJ, Tong Z (2010) Investigating potential water quality impacts of fungicides used to combat soybean rust in Indiana. Water Air Soil Poll 207:273-288

4. Guo J, Song WH, Ding F, Zhen L, Che XY, Zhang JH, Lian J (2009) Acute toxicity study of triazole fungicides exposure to Daphnia magna. Acta Scientiarum Naturalium Universitatis Nankaiensis 42(3):76-42 (in Chinese with English abstract)

5. Hasan MK, Shahriar A, Jin KU (2019) Water pollution in Bangladesh and its impact on public health. Heliyon 5:21-45

6. Haas M, Justus K (2004) Metabolism of prothioconazole (JAU 6476) in animals and plants. Pflanzenschutz-Nachrichten Bayer 57: 207-224

7. Hellpointner E, Borchers H (2004) Behaviour of prothioconazole (JAU 6476) in the environment. Pflanzenschutz-Nachrichten Bayer 57:163-180

8. Hoaip PM, Sebesvaril Z, Minh TB, Viet PH, Renaud FG (2011) Pesticide pollution in agricultural areas of northern Vietnam: case study in hoang liet and Minh Dai communes. Environ Pollut 159: 3344-3350

9. Hu Y, Chen XJ, Yang K, Lin DH (2018) Distinct toxicity of silversilver nanoparticles and silver nitrate to Daphnia magna in M4 medium and surface water. Sci Total Environ 618: 838-846

10. Kim HY, Lee MJ, Yu SH, Kim SD (2012) The individual and population effects of tetracycline on Daphnia magna in multigenerational exposure. Ecotoxicology 21(4):993-1002

11. Kuhn R, Pattard M, Pernak KD, Winter A (1989) Results of the harmful effects of water pollutants to Daphnia magna in the 21 day reproduction test. Water Research Oxford 23:501-510

12. Liu JM, Liu JN, Chen YW, Wang L, Shen SB (2018) Acute and chronic toxicity of tetrabromobisphenol A and tribromophenol on Daphnia magna. J Environ Sci 35(6):1946-1954

13. OECD (2006) Guidelines for Testing of Chemicals: Daphnia sp. Acute Immobilisation Test. Paris: OECD

14. OECD (1998) Guidelines for the testing of chemicals, Daphnia magna: Reproduction test, OECD guideline 211[R]. Paris: OECD

15. Paul P, Salgado J, Bergstrom G, Bradley G, Byamukama E, Byrne A, Chapara V, Cummings J, Chilvers M, Dill-Macky R (2019). Integrated effects of genetic resistance and prothioconazole + tebuconazole application timing on fusarium head blight in wheat. Plant Dis 103:223-237

16. Rodriguez P, Martinez-Madrid M, Cid A (2006) Ecotoxicological assessment of effluents in the Basque Country (Northern Spain) by acute and chronic toxicity tests using Daphnia magna Straus. Ecotoxicology 15:559-572

17. Sjerps RMA, Kooij PJF, Loon AV, Wezel APV (2019) Occurrence of pesticides in Dutch drinking water sources. Chemosphere 235, 510-518.

18. Sinclair CJ, Boxall ABA (2003) Assessing the ecotoxicity of pesticide transformation products. Environ Sci Technol 37:4617-4625

19. Trösken ER, Adamska M, Arand M, Zarn JA, Christopher P, Wolfgang V, Lutz WK (2006) Comparison of lanosterol-14a-demethylase (CYP51) of human and Candida albicans for inhibition by different antifungal azoles. Toxicology 228:24-32

20. Trösken ER, Ellen S, Werner KL, Wolfgang V, Christopher $P$ (2004) Quantitation of lanosterol and its major metabolite FF-MAS in an inhibition assay of CYP51 by azoles with atmospheric pressure photoionization based LC-MS/MS. J Am Soc Mass Spectr 15:1216-1221

21. Wang PP, Li MM, Liu XG, Xu J, Dong FS, Wu XH, Zheng YQ (2016) Degradation of cyflumetofen and formation of its main metabolites in soils and water/sediment systems. Environ Sci Pollut R 23:23114-23122 
22. Xie Y, Jiang H, Chang J, Wang Y, Li J, Wang H (2019) Gonadal disruption after single dose exposure of prothioconazole and prothioconazole-desthio in male lizards (Eremias argus). Environ Pollut 255:113297

23. Yuan CJ (2012) Individual and combined toxic effects of chloroacetonitrile, aniline, and malathion on water flea. Dissertation, Taiwan:National Chiao Tung University 68-69 (in Chinese with English abstract)

24. Zhai WJ, Zhang LL, Cui JN, Wei YM, Wang P, Liu DH (2019) The biological activities of prothioconazole enantiomers and their toxicity assessment on aquatic organisms. Chirality 31:468-475

25. Zhang Z, Gao B, Li L, Zhang Q, Xia W, Wang M (2018) Enantioselective degradation and transformation of the chiral fungicide prothioconazole and its chiral metabolite in soils. Sci Total Environ 634:875-883

26. Zhang Z, Zhang J, Zhao X, Gao B, He Z, Li L, Shi H, Wang M (2020) Stereoselective uptake and metabolism of prothioconazole caused oxidative stress in zebrafish (Danio rerio). J Hazard Mater 396:122756 